\title{
Innovation activity of corporations in emerging economies
}

\author{
Ekaterina N. Soboleva ${ }^{1 a}$, Mikhail V. Chikov², and Anastasia S. Zaikovskaya ${ }^{1}$ \\ ${ }^{1}$ National Research Tomsk Polytechnic University, Tomsk, 634050, Russia \\ ${ }^{2}$ National Research Tomsk State University, Tomsk, 634050, Russia
}

\begin{abstract}
The paper considers macro parameters of corporation innovation activity in the BRICS countries. The authors determine transnational corporation behavior strategies in the context of creating and transferring new knowledge, where developed countries (the USA, European countries and Japan) play an important role and take a leading position in this process. Companies from emerging economies focus on using and adopting innovations. The reason for this is that knowledge "is coded" specifically, consequently the participants of its exchange have to be in similar intellectual space. Nevertheless, the market-leading corporations from the BRICS countries join the world chains of innovation creation, building their networks to satisfy their branches needs concerning technological decisions and personnel training
\end{abstract}

\section{Introduction}

Developing of the BRIC countries has become a prominent issue in the last decade. The term was created by J. O'Neill to identify four largest emerging economies - Brazil, Russia, India, and China [1]. A few years ago, South Africa joined BRIC.

Their economic potential is getting increasing attention in the scientific community. Whereas experts discuss their prospect of becoming economic and political power $[1,2]$, skeptics argues that BRICS has a heterogeneous structure, and these countries face different problems in realizing their economic potential [3].

A central theme in the analysis of emerging economies, especially BRICS, is the importance of innovation-driven development [4]. Since the end of the XX century, they have been making efforts to transform their innovation system and to build an infrastructure for domestic innovation activities.

Corporations are playing the key role in these processes. Their activity is determined by various factors such as institutional framework, mechanism of interaction between large firms, state, and research centers, corporate culture, market share, and others factors.

The paper proposes defining some parameters of innovation intensity in the BRICS countries. The paper is divided in three sections. Section I takes a brief look at the macroeconomic context of innovation development in BRICS. In Section II, we concentrate on the role of the state in national innovation system. Knowledge use and creation strategies, performed by TNCs in emerging economies, are described in Section III.

\section{Macroeconomic indicators innovation development in BRICS}

In the last decade, the transnational corporations (TNCs) from emerging economies have strengthen their presence on the world market trying to secure top positions in domestic economy and to get access to the foreign technologies and resources. TNCs have increasingly globalized their innovation activity.

Although, its measure is hindered because of the lack of the specific data, we can use some macroeconomic indicators, such as gross expenditure on research and development (GERD), charges for use of intellectual property etc.

The BRICS countries steadily increase the expenditure on research and development (R\&D).

Table 1. GERD in BRICS countries, 2011-2014

\begin{tabular}{|c|c|c|c|c|c|c|c|c|}
\hline \multirow{2}{*}{} & \multicolumn{2}{|c|}{2011} & \multicolumn{2}{c|}{2012} & \multicolumn{2}{c|}{2013} & \multicolumn{2}{c|}{2014} \\
\cline { 2 - 9 } & Bln & $\%$ & Bln & $\%$ & Bln & $\%$ & Bln & $\%$ \\
& PPP\$ & GDP & PPP\$ & GDP & PPP\$ & GDP & PPP\$ & GDP \\
\hline Brazil & 27,9 & 1,2 & 29,5 & 1,25 & 31 & 1,3 & 33 & 1,3 \\
\hline Russia & 35,7 & 1,48 & 37 & 1,48 & 38 & 1,5 & 40 & 1,5 \\
\hline India & 38,4 & 0,85 & 40,3 & 0,85 & 42 & 0,85 & 44 & 0,9 \\
\hline China & 177,3 & 1,55 & 197,3 & 1,6 & 258 & 1,9 & 284 & 2,0 \\
\hline $\begin{array}{l}\text { South } \\
\text { Africa }\end{array}$ & 5,3 & 0,95 & 5,5 & 0,95 & 6 & 1,0 & 6 & 1,0 \\
\hline
\end{tabular}

$\overline{{ }^{a} \text { Corresponding author: soboleva88 }} @$ tpu.ru 
In particular, China demonstrates the growth of R\&D-intensity and takes the 2nd place in the world spending approximately 300 billion US dollars on R\&D (table 1). The experts expect that China will surpass the U.S. by about 2022. [5]

Table 2. Charges for use of intellectual property in the BRICS countries, the USA, and Japan (billion US dollars)

\begin{tabular}{|l|l|l|l|l|l|l|}
\hline \multirow{2}{*}{} & \multicolumn{2}{|c|}{2012} & \multicolumn{2}{c|}{2013} & \multicolumn{2}{c|}{2014} \\
\cline { 2 - 7 } & $\begin{array}{l}\text { Payment } \\
\text { s }\end{array}$ & Receipts & $\begin{array}{l}\text { Payment } \\
\text { s }\end{array}$ & Receipts & Payment & Receipts \\
s & \\
\hline Brazil & 3666,5 & 510,7 & 3668,6 & 597,2 & 5922,7 & 375,1 \\
\hline China & 17748,9 & 1044,1 & 21033,1 & 886,7 & $\ldots$ & $\ldots$ \\
\hline India & 3990,1 & 321,4 & 3904,0 & 445,6 & 4848,7 & 658,7 \\
\hline Russia & 7629,3 & 664,2 & 8370,8 & 737,9 & 8021,4 & 665,8 \\
\hline $\begin{array}{l}\text { South } \\
\text { Africa }\end{array}$ & 2017,1 & 124,9 & 1936,8 & 120,0 & 1732,0 & 116,5 \\
\hline Japan & 19897,6 & 31892,3 & 17831,4 & 34587,0 & 20934,9 & 36832,6 \\
\hline USA & 38660,0 & 124439 & 38999,0 & 127927 & 42124,0 & 130361,0 \\
\hline
\end{tabular}

Actually, firms from emerging economies rank among the largest users of the intellectual property. Based on statistical data $[6,7]$, we can conclude that in contrast to developed countries payments for using patents, trademarks, copyrights, industrial processes and designs etc. in emerging economies exceed receipts for using proprietary rights (table 2 ).

Nowadays TNCs from emerging economies got access to the world market owing to low-cost production, but it results in aggravation of competition between domestic and foreign capital [5].

Therefore, they have to reach their competitiveness through increasing R\&D-activity and maintain cost leadership at the same time. In general, emerging economies (except China) demonstrate lower innovation intensity than developed ones. Although China focuses on adopting innovations, it creates them as well. In 2009-2012 the receipts for use of intellectual property in Chinese economy were redoubled.

The BRICS countries have different innovation potential. Russia produces more than 3000 scientists per million people. It is a bit less than in Europe or the USA, whereas India, Brazil continue lagging behind those figures (Figure 1).

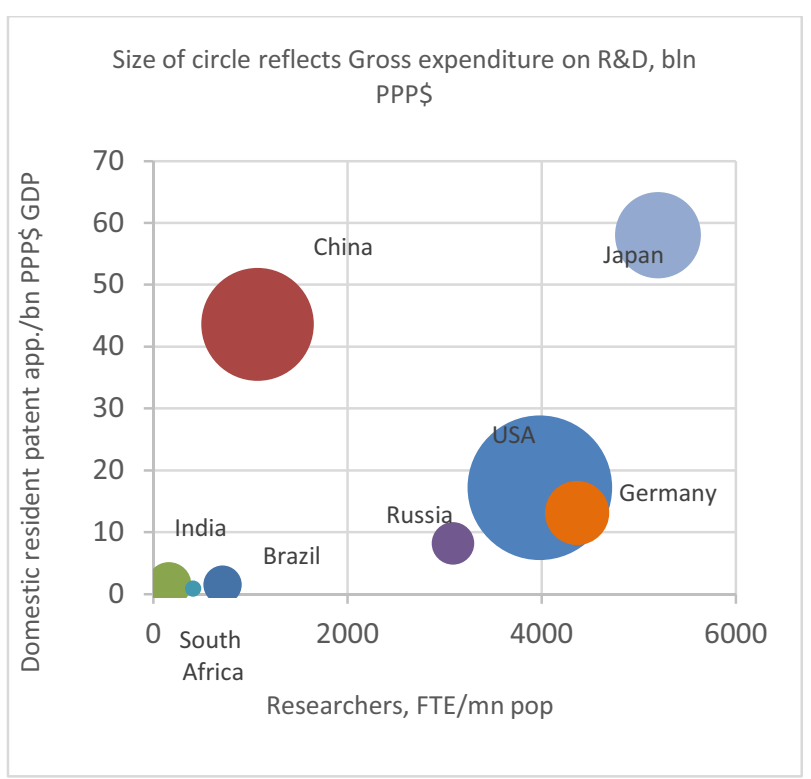

Fig. 1. Indicators of innovation activity

Nevertheless, the considerable part of large Indian and Brazilian firms implement innovations, but their types are different across countries. For instance, in Brazil the product/process and marketing/organizational innovations predominate. Indian companies concentrate on marketing/organizational innovations only (Figure 2) [8].

Apparently, such differences are determined by the national innovation system. Brazilian and Indian markets are attractive for foreign TNCs because of their capacity. It leads to implementation of marketing/organizational innovations. High-level availability of education in Russia results in more applications for a patent.

However, the quality of these innovations is relatively low. The most part of Russian corporations tends to perform a strategy of innovative imitation. For instance, they have bought new equipment or implemented existing business models in order to make production process more flexible and efficient. Nevertheless, cost reduction or employment security were not taken into consideration.

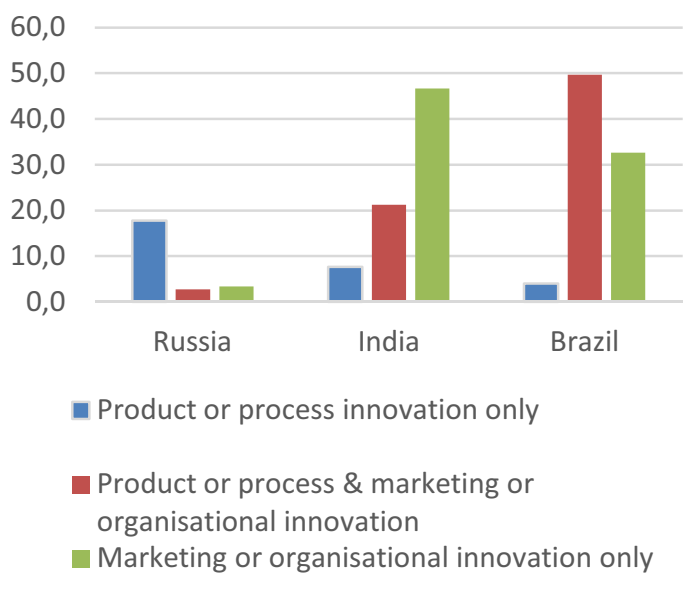

Fig. 2. Types of innovations performed by large firms, $\%$ 
It should be emphasized, that innovation intensity in Russian corporations was higher when they were used to invest in $\mathrm{R} \& \mathrm{D}$, and have technical culture. Consequently, innovation activity is peripheral to corporate strategy of the mainly part of Russian large firms, and it is primarily aimed for increase of financial effectiveness whereas labor productivity grows slowly. Nowadays labor productivity in Russian corporations is four times lower than in the USA, three times lower than in European countries, and 1.6 times lower than in China.

Foreign TNCs exert a substantial impact on innovation activity in emerging economies. They compete strongly against the domestic firms, and consequently encourage implementing of innovations.

The economic relationship between foreign and domestic capital is contradictive. On the one hand, foreign TNCs are interested in the acceptable rate of return and increase of their asset value. On the other hand, they do not aim at maintaining the welfare in a recipient country.

The domestic firms contact with foreign TNCs in the following forms [9]:

- Production of the similar goods;

- Supply of raw materials and components for foreign firms;

- Use of raw materials and components from foreign firms;

- Distribution of TNCs' products on the domestic market.

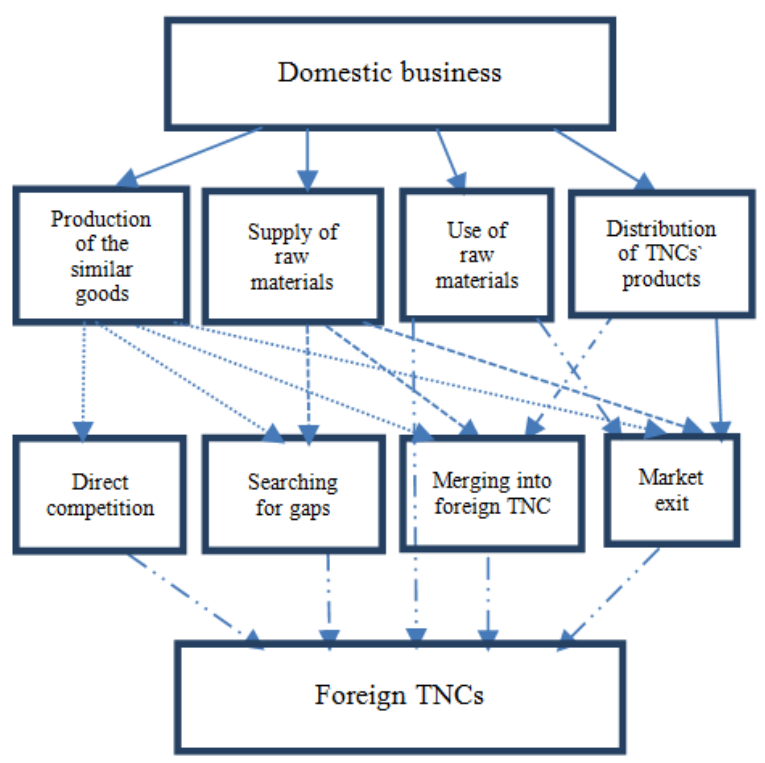

Fig.3 Economic relationship between domestic and international business [9, p. 204]

In general, we can distinguish some competitive strategies performed by domestic firms (Figure 3):

- Compete against foreign TNCs;

- Make a search for gaps in the market;

- Merge into foreign TNC;

- Market exit.
These strategies (except market exit) assume that firms have to adapt their behavior to the new circumstances. Therefore, we can suggest that high demand for marketing and organizational innovations in emerging economies is determined by increased competition on the domestic market.

Interacting with international business, firms get access to a range of innovations from new products and technologies ("vertical" investment) to new business models ("horizontal" investment). Nowadays, TNCs prefer to inject "vertical" investment, which are aimed at value chain creation. However, they pay attention to the social capital formation to decrease bargaining costs.

Thus, we emphasize that innovation activity in emerging economies depends on cooperation between key actors: foreign and domestic firms, and state as well.

\section{State and innovation activity of the large firms}

It is widely agreed that the most important economical functions of the state are to establish contract enforcement institutions, maintain economic stability, and provide social welfare.

Performing these functions, state establishes property rights institutions. Firstly, it means that state controls access to scarce goods, especially to non-renewable resources, in order to meet the society's needs.

Secondly, state has to define property rights. Thus, government intervention in market process is based on the state's enforcement monopoly.

Thirdly, representing social interests, state has a right to limit the use of privet property in order to provide opportunities for economic growth and development. In spite of the fact that regulatory taking has been criticized, it can, under certain conditions, promote innovations.

Fourthly, state, inducing institutional change, can create new forms of interaction among the existing agents and institutions.

The analysis of property rights institution in Russian economy gives us evidence that inefficient interaction between state and corporations leads to innovation activity decrease.

It results in rent-seeking behavior and disparity between corporate actors. Stakeholders, who are taking real corporate control, serve their interests at the expense of other stakeholders. This phenomenon can be described as an institutional trap [10].

Within the trap, economic actors strive to achieve good financial results to obtain momentary advantage. However, they are not able to create permanent innovation culture.

Nevertheless, state is significantly increasing its influence on economic activity in developing countries. For instance, it spends a substantial part of investment into fundamental research. This gives us evidence that the state tries to perform innovation activity instead of private business. R\&D: 
- Increase of the market share in the global economy;

- Implementation of industrial policy and promotion of economic activity;

- Augmenting of country`s innovation potential;

- Improvement in labor force quality.

Thus, the state has to reconcile the interests of society, domestic and foreign business.

\section{Knowledge transfer strategies: adoption vs. creation}

There are two strategies of knowledge use and creation, practicing by TNCs from emerging economies [11]. The first (asset-exploiting strategy) involves a transfer of intellectual capital, created in the home country, to TNC`s overseas departments. Within the asset-exploiting strategy, there are two types of firms:

1. Modifiers - they do not conduct a full R\&D-cycle, but they adopt innovation to improve their product and processes.

2. User of technologies - they borrow innovations developed by other firms.

As a result, firms-recipients gain access to the new technological solutions. Such activity has been spread worldwide, especially in the BRICS countries with their developing markets. The reason for this is a low degree of national innovation system competitiveness. Moreover, TNCs are often interested only in finding new markets for their product in host countries [12].

The second strategy (asset-augmenting) means that knowledge was created by overseas department of TNCs and transferred to the headquarters to use within the TNCs. Implementation of this strategy requires building inter-firm chains for information exchange.

The key problem is that knowledge is coded in special way; therefore, all participants of its transfer have to be in the similar intellectual space. That is why the most TNCs concentrate their innovation activity in the Triad (USA, Europe, and Japan).

Nevertheless, large firms from emerging economies proceed with the asset-augmenting strategy and create their own innovation clusters. Being technological leaders, TNCs feel up to collaborate with the different subjects of national innovation system (universities, firms etc.) and promote demand for $R \& D$, and staff training as well.

Some companies from BRICS succeed in this strategy. For instance, Embraer (Brazilian $3^{\text {rd }}$-biggest aerospace company in the world) plays a key role in value added chain united relationships between design engineers, components suppliers, and producers. Furthermore, nearly $98 \%$ of components are produced abroad, but assembly process is located in Brazil.

The main contribution to the Embraer's success was made by special innovation infrastructure, created in "the Technology Valley" São José dos Campos. Supporting innovation activity includes collaboration with research centers and institutes.

According to agreements between Embraer and SENAI (National Industrial Learning Service), the service provided training for 40 students on behalf of the company. In return, Embraer had to build a modern laboratory for SENAI in São José dos Campos to carry out investigations in the area of telecommunication [13].

Therefore, in spite of a relatively small size TNCs from emerging economies try to increase innovation activity and incorporate into global chains of creating and transferring knowledge.

\section{Conclusion}

We can state that there are different trends in processes of innovations creation and implementation in emerging economies.

On the one hand, TNCs operated in technology intensive fields (such as IT, pharmaceuticals industry etc.) have strong positions on domestic and, in some cases, on the world markets. These branches are characterized by a high level of expenditure on R\&D, patent application and grant activity and competitive ability.

On the other hand, they have come short of innovation potential usage; positive dynamics of innovation development is mostly connected with particular qualities of rapid growth on certain world markets.

In contrast to the developed countries, state plays key role in innovation systems of emerging economies. Besides security and enforcement of property rights, it has to spend a significantly amount of money to encourage innovations because of high vulnerability of developing economies. Thus, state investment substitutes for privet ones, especially during the economic crisis.

\section{Acknowledgement}

This research was financially supported by the National Research Tomsk Polytechnic University

\section{References}

1. J. O`Neill, Goldman Sachs Glob. Econ. Paper, 66, (2001)

2. H.F. Cheng, M. Gutierrez, A.Mahajan, Y. Shachmurove, M. Shahrokhi, Glob. Finance J., 18, 143-156 (2007)

3. L.M. Jacobs, R.V. Rossem, J. of Policy Modeling, 36, 47-66 (2014)

4. Global Innovation Index 2015. Effective Innovation Policies for Development (Geneva: WIPO, 2015) www.globalinnovationindex.org/userfiles/file/report pdf/gii-full-report-2015-v6.pdf

5. 2014 Global R\&D Funding Forecast (Advantage Business Media, 2014) www.battelle.org/docs/tpp/2014_global_rd_funding _forecast.pdf

6. Charges for the use of intellectual property, payments (The World Bank Group, 2015) www.data.worldbank.org/indicator/BM.GSR.ROYL .CD/ countries 
7. Charges for the use of intellectual property, receipts (The World Bank Group, 2015) www.data.worldbank.org/indicator/BX.GSR.ROYL. $\mathrm{CD} /$ countries

8. OECD Science, Technology and Industry Scoreboard (OECD, 2015) www.oecd.org/sti/scoreboard.htm

9. I.A. Petinenko, N.A. Redchikova, E.N. Soboleva, M.V. Chikov, TSU J., 381, 202-216 (2014)

10. V. Polterovich, Institutional traps and transition (CEMI, 1999)

11. F. Rocha, A.U. Ruiz, Transn. Corp., 20, 34 - 35 (2011)

12. Russia in the polycentric world / Rossija $v$ politsentrichnom mire (Moscow: Ves` mir, 2011)

13. J.E.Cassiolato, R. Bernardes, H. Lastres, Transfer of Technology for Successful Integration into the Global Economy. A case study of Embraer in Brazil (New York, Geneva: United Nations, 2002) 